\title{
Prevalence of peri-implant diseases in fully edentulous patients restored with four implants supported fixed full arch prosthesis: a literature review
}

\author{
Mariam Margvelashvili-Malament ${ }^{1}$, Steven E. Eckert ${ }^{2}$ \\ ${ }^{1}$ Department of Prosthodontics, Tufts University School of Dental Medicine, Boston, MA, USA; ${ }^{2}$ Mayo Medical School, Rochester, MN, USA \\ Contributions: (I) Conception and design: SE Eckert; (II) Administrative support: M Margvelashvili-Malament; (III) Provision of study materials or \\ patients: M Margvelashvili-Malament; (IV) Collection and assembly of data: M Margvelashvili-Malament; (V) Data analysis and interpretation: Both \\ authors; (VI) Manuscript writing: Both authors; (VII) Final approval of manuscript: Both authors. \\ Correspondence to: Dr. Steven E. Eckert, DDS, MS. Professor Emeritus, Mayo Medical School, Rochester, MN, USA. Email: seeckert@me.com.
}

\begin{abstract}
Background and Objective: "All-on-four" is a popular protocol due to shortened treatment time and financial feasibility. This has also been justified by the high survival rates of $95.4 \%$ over 7 years. However, the prevalence of peri-implant diseases is still not well explored. A review of the literature was performed to identify prevalence of peri-implant diseases in patients restored with full-arch four implants supported fixed restorations.
\end{abstract}

Methods: This review used electronic literature search of PubMed database to obtain recent and the most relevant English-language scientific information from previous systematic reviews, consensus statements, and clinical trials published between 1995-2021.

Key Content and Findings: Due to an inability to identify a study, or studies, that answer the PICO question or provide conceptual homogeneity, no Meta-Analysis was conducted. Based on the limited number of articles that were included in this study peri-implant mucositis ranged up to $30.2 \%$ at the patient and upto $18.3 \%$ at the implant level, while peri-implantitis ranged up to $25 \%$ at the patient and up to $7.2 \%$ at the implant level with 5-10 years of follow-up.

Conclusions: Despite the prevalence of peri-implant diseases, the all-on-four treatment modality for completely edentulous arches has moderately high long- and medium-term survival outcomes (implants and prosthesis). Strict maintenance and follow-up are highly recommended to minimize biologic complications.

Keywords: Dental implants; fixed dental prostheses; implant supported fixed restoration; all-on-four; peri-implant disease

Received: 14 July 2021; Accepted: 26 November 2021; Published: 10 March 2022.

doi: $10.21037 /$ fomm-21-83

View this article at: https://dx.doi.org/10.21037/fomm-21-83

\section{Introduction}

Restoring fully edentulous jaws with implant supported fixed prosthesis allows the restoration of function (phonetics and mastication), esthetics, and patients' quality of life. This type of treatment is well validated by substantial body of scientific and clinical evidence (1-5). Implant 5-10-year survival rates supporting full-arch prosthesis can be as high as $98 \%(6,7)$. However, the focus of the older articles was implant osseointegration and overall survival, leaving some of the biologic complications unreported. Implant success has been re-defined, and newer evaluation parameters, such as soft tissue health, have been identified (8). Recent systematic review reported prevalence of peri-implant diseases of approximately $29 \%$ (9). This clearly highlights the importance of understanding peri-implant diseases, their cause, prevalence, and relationship between different types of prostheses.

Peri-implant diseases have been classified into two major 
categories: peri-implant mucositis and peri-implantitis. Both are characterized with the biological complication and inflammation of peri-implant soft tissues, while periimplantitis also involves bone loss around the implants (10) with observation of bleeding on probing and suppuration. Although, it is well established the periodontal and periimplant inflammation is associated with the presence of certain bacteria $(11,12)$, other factors and clinical confounding variables have been identified. Specifically, smoking, previous periodontal disease, poor oral hygiene, and residual excess cement have all been linked with periimplant diseases (13). Recent studies have also focused on the prosthetic features like restoration emergence profile and angle, showing that over-contoured restorations have higher risk of developing peri-implantitis $(14,15)$.

Although, bone and soft tissue augmentation procedures are well established, they are still associated with longer treatment time, higher costs, and risk of morbidity. A technique that allows the use of fewer implants with no bone grafting has been recognized as the "all-on-four" concept. It involves placement of four implants into fully edentulous jaw with minimal amount of native bone volume. Two anterior implants are placed axially, while two posterior implants are tilted (15-45 degrees) to take advantage of more dense bone available in anterior jaw and extend Anterior to Posterior spread $(16,17)$. This protocol was merged with immediate loading protocol, involving insertion of four implant supported fixed fullarch prosthesis on the day of surgery (All-on-four treatment concept, Nobel Biocare AB, Goteborg, Sweden).

The combination of shortened treatment time with financial feasibility made the protocol very popular. The wide-spread use of the concept has further been justified by the high survival rates of $95.4 \%$ over 7 years $(1,6,7,17-19)$. However, the prevalence of peri-implant diseases is still not well explored. Although, systematic reviews hold higher scientific evidence, if the studies are heterogenous, they could be inconclusive. Therefore, the current article represents a literature review on the prevalance of periimplant diseases of full-arch "all-on-four" fixed restorations. This review used electronic literature search of PubMed database to obtain recent and the most relevant scientific information from previous systematic reviews, consensus statements, and clinical trials.

We present the following article in accordance with the Narrative Review reporting checklist (available at https://fomm. amegroups.com/article/view/10.21037/fomm-21-83/rc).

\section{Methods}

The review protocol was developed based on the elaborated PICO question: What is the prevalence of peri-implant disease in patients having at least one implant supported full-arch fixed dental prosthesis supported by four implants? And what are the prosthesis related features that could influence the outcome (peri-implant mucositis and periimplantitis)?

Search terms were developed based on the PICO question and PubMed search was conducted. To meet the eligibility requirements the following inclusion criteria were applied: Human studies, randomized controlled clinical trials, prospective and retrospective clinical trials, consensus statements, and systematic reviews.

Three stage screening process was done by two independent authors (M.M.M and S.E.) and is summarized in Table 1. Titles derived from the initial search were screened and in-vitro studies, studies not related to the review topic and duplicates were excluded. Obtained abstracts were further screened for inclusion. Based on the selection of abstracts, articles were then obtained in full text assuming the article met inclusion criteria. All full text articles were carefully read and analyzed by the same two investigators independently. No language restriction was used to widen the search but when full text was not available in English, article was excluded from the analyses. Any disagreement on each screening stage was resolved by discussion.

\section{Definition of peri-implant diseases}

In earlier times peri-implantitis was defined as the presence of inflammation in the soft tissues and the loss of supporting bone around osseointegrated implant (20). However, the new classification system of periodontal and peri-implant diseases described peri-implant disease as two distinct conditions of peri-implant mucositis and peri-implantitis (21). Peri-implant mucositis is associated with bleeding on probing and other visual signs of inflammation. Usually, it is associated with the plaque and can be reversed with measures aimed at reducing the plaque. It has no associated bone loss (22). Peri-implantitis is defined as a pathologic condition and inflammation of soft tissues and loss of bone around implants (13). Because, peri-implant diseases were not clearly defined prior to the introduction of new classification system, there seems to be variability in the reports of the clinical studies and not all the studies refer to 
Table 1 Summary of the search strategy

\begin{tabular}{ll}
\hline Items & Specification \\
\hline Date of Search (specified to date, month and year) & 03/01/2021-04/01/2021 \\
Databases and other sources searched & PubMed \\
$\begin{array}{l}\text { Search terms used (including MeSH and free text search } \\
\text { terms and filters). Note: please use an independent }\end{array}$ & $\begin{array}{l}\text { Implant supported fixed prosthesis OR complete-arch implant supported } \\
\text { fixed prosthesis OR full-arch implant retained prosthesis OR all-on-four }\end{array}$ \\
$\begin{array}{l}\text { supplement table to present detailed search strategy of } \\
\text { one database as an example }\end{array}$ & $\begin{array}{l}\text { AND biological complications OR marginal bone loss OR peri-implantitis } \\
\text { OR implant failure OR prosthesis complication OR reconstruction failure }\end{array}$ \\
$\begin{array}{l}\text { Timeframe } \\
\text { Inclusion and exclusion criteria (study type, language }\end{array}$ & $\begin{array}{l}\text { Human studies, randomized controlled clinical trials, prospective and } \\
\text { restrictions etc.) }\end{array}$ \\
$\begin{array}{l}\text { retrospective clinical trials, consensus statements, and systematic reviews } \\
\text { in English language }\end{array}$ \\
$\begin{array}{l}\text { Selection process (who conducted the selection, whether } \\
\text { it was conducted independently, how consensus was }\end{array}$ & $\begin{array}{l}\text { Three stage screening process was done by two independent authors } \\
\text { (M.M.M and S.E.). Any disagreement on each screening stage was resolved } \\
\text { obtained, etc.) }\end{array}$ \\
$\begin{array}{l}\text { by discussion } \\
\text { Any additional considerations, if applicable }\end{array}$ & NA \\
\hline
\end{tabular}

the same definition of peri-implant diseases. Some focus on clinical parameters like marginal bone resorption, probing depth, bleeding on probing, plaque and calculus around implants. While failing to classify existing inflammation as peri-implant mucositis or peri-implantitis.

\section{Results}

Due to the inability to identify a study, or studies, that fully answer the PICO question or provide conceptual homogeneity, no Meta-Analysis was conducted.

The following articles were identified and included for discussion.

A study analyzing 7-year survival rate of mandibular allon-four concept prosthesis reported implant survival of $95.4 \%$. Out of 1,296 implants 18 failed (16 had mobility and loss of osteointegration and 2 had persistent inflammation). Mean marginal bone level at the apical position of the implant-abutment interface was $1.81 \mathrm{~mm}$ at 5 years. The authors conducted regression analysis to identify confounding variables associated with marginal bone loss $>2.8$. Smoking and presence of systemic condition was associated with higher bone loss. The authors did not report incidence of peri-mucositis or periimplantitis. Prosthetic survival rate was as high as $99.7 \%$ (18).

Balshi conducted a retrospective study of 152 patients with 200 arches and 800 implants. They reported 97.8\% cumulative implant survival and $99.0 \%$ prosthesis survival rate. No significant differences were seen between arches, gender, and implant orientation (axial vs. tilted). Although, the study holds value for analyzing implant survival rate as well as comparing clinical variables, no prevalence of periimplant diseases was reported (1).

In a retrospective study analyzing 86 patients treated with immediately loaded 95 All-on-four concept prosthesis reported peri-implant mucositis in $30.2 \%$ of the patients and peri-implantitis in $10.4 \%$ of the patients. At the implant level, $18.3 \%$ of the implants were recorded with perimucositis, while $6.3 \%$ with peri-implantitis. Additionally, $32.3 \%$ of the cases demonstrated hygienic problems (23).

Li et al. reported result of 80 implants placed in 20 arches and restored with all-on-four concept with average follow-up time of 5 years. Cumulative survival rate of the implants was $98.75 \%$. One tilted implant failed due to periimplantitis. Survival of definitive prosthesis was 100\% and $85 \%$ of provisional prosthesis. Peri-implantitis was seen in only $1.25 \%$ of the implants, which is significantly lower than the results of other studies (24).

Lopes et al. analyzing 92 implants restored with all-onfour concept reported peri-implantitis at implant level to be as low as $2.1 \%$ and $8.7 \%$ at patient level (25). Their followup study reported $30.6 \%$ at the patient and $12 \%$ at the implant level to have biological complications (26). Out of the implant level complications, $1.7 \%$ was peri-mucositis (described as soft tissue inflammation) and $1.8 \%$ was periimplantitis (described as implant infection). They also reported $22.5 \%$ of the patients to have had peri-implant pathology, like bone defect, pocket formation, bleeding on 
probing, and mucosal inflammation.

When a recent systematic review analyzed prevalence of peri-implant diseases in implant supported fixed fullarch prostheses peri-implant mucositis ranged up-to $13.7 \%$ of the patients and up-to $12 \%$ of the implants. While the prevalence of peri-implantitis ranged up-to $25 \%$ at the patient and up-to $7.2 \%$ at the implant level. Patients seem to demonstrate the tendency of developing peri-implantitis at least after 1 year of follow-up (9).

\section{Discussion}

The present review aimed to evaluate the prevalence of peri-implant diseases (peri-mucositis and peri-implantitis) in patients restored with full-arch implant supported allon-four restorations. Based on the articles analyzed, fully edentulous patients restored with all-on-four prosthesis appear to develop peri-implant mucositis in up-to $30 \%$ and peri-implantitis in $25 \%$ with $5-10$ years of follow-up. However, one should consider that there was high variation in the prevalence values among the studies. This can be explained by various authors using different definitions and evaluation criteria for peri-implant diseases. For instance, Lopes et al. reported peri-implantitis to be present in $8.7 \%$ of the patients (25). While in their follow-up study biological complications were seen in $30.6 \%$ of the patients (26). Out of the implant level complications, $1.7 \%$ was perimucositis (described as soft tissue inflammation) and 1.8\% was peri-implantitis (described as implant infection). Then the authors reported $22.5 \%$ of the patients to have had periimplant pathology, like bone defect, pocket formation, bleeding on probing, and mucosal inflammation. It is confusing to understand how the authors delineated implant infection from implant pathology, which with current standards would fall under the category of peri-implantitis (21).

As patients age, the loss of natural teeth becomes a critical factor towards maintenance of health. Loss of natural teeth may result in diminished chewing capacity which could cause the dental patient to fall into a category of functional malnutrition (27). The inability to chew may interfere with the overall health and well-being of the patient.

Dentists have been tasked with the responsibility to maintain the natural teeth by preventing tooth loss or restoring function and esthetic in instances where teeth are already lost. Restoring fully edentulous jaws with implant supported fixed prosthesis allows the restoration of function (phonetics and mastication), esthetics, and patients' quality of life. This type of treatment is well validated by substantial body of scientific and clinical evidence (1-5).

Various clinical techniques were utilized to define the ideal number and distribution of implants. Krekmanov et al. described a process whereby the posterior implants were placed at an angle with the coronal aspect of the implant more distal than the apical portion thereby creating a longer implant in bone (28). Using four implants to support the full arch prosthesis provided the patient with adequate strength, implant distribution and a predictable replacement of teeth that could be placed on the day that natural teeth were removed $(6,28)$.

Peri-implant mucositis is implicated in $0 \%$ to $65 \%$ while peri-implantitis, the more pathogenic risk factor, has been reported from $1 \%$ to $47 \%$ of patients with implants. A few different bacterial species have been implicated in contributing peri-implantitis. Gram negative bacteria and Staphylococcus aureus being the most noticeable. Periimplantitis is generally evident with soft tissue inflammation, bleeding on probing, redness, erythema, suppuration, separation on probing, probing depth of up to $6 \mathrm{~mm}$ and bone loss (10).

The earliest generation of dental implants were thought to be resistant to deterioration of the soft tissue as it contacted the implant. Over time, reports of soft tissue breakdown adjacent to the implant became more prevalent. It is unclear today whether the breakdown is secondary to changes in the biofilm resulting in an unfavorable host environment or the adverse reaction could represent a metal contamination that may be derived from the manufacturing process $(29,30)$.

The relationship between periimplantitis and the Allon-four does not appear to be exacerbated by either of the two processes. Management of the periimplantitis may be achieved through treatment utilizing implantoplasty and improved oral hygiene. In some instances, this will not be a manageable problem but for most patients it appears manageable (6,7,17-19).

Other factors than bacteria are being highlighted in literature to be contributing to the development of periimplant diseases. Smoking and previous periodontal disease are linked with peri-implant diseases (13). Perhaps, more attention should be paid to ideal 3-dimensional (3-D) implant positioning and cleansable prosthetic design in the patients with existing risk factors. Additionally, poor oral hygiene and residual excess cement are also associated with higher prevalence of peri-implant diseases (13). Recently, studies have also focused on the prosthetic features like 
restoration emergence profile and angle, showing that over-contoured restorations have higher risk of developing peri-implantitis $(14,15)$. This once again highlights the importance of prosthetic features, cleansability, and maintenance protocols. In fact, a study assessing outcome of four implant supported full-arch fixed prosthesis concluded that systemic hygienic protocols and maintenance was effective in keeping low incidence of peri-implant diseases and controlling plaque to avoid hygienic problems (31).

One should also consider the materials that are being used. Acrylic resin is characterized with higher plaque accumulation and degradation rate (32). With new protocols, involving Zirconia restorations reduced plaque accumulation can be expected (33). This warrants future studies.

In summary, the cumulative survival rate of implants supporting all-on-four concept restorations is very high. However, when taking closer look and considering new evaluation criteria of success rate (8) and soft tissue health status the outcome changes. It demonstrates that implant supported full-arch prostheses are not complication-free and soft and hard tissue complications like peri-implant mucositis and peri-implantitis may occur in up-to $30 \%$ of the patients over $5-10$ years.

Implant dentistry is evolving and digital implant surgery is becoming standard in everyday practice. Thus more prosthetically driven implant placement and better Computer-Aided Design (CAD) prostheses with cleansable and retrievable features should be planned and delivered (34). We all have to learn from the accumulated scientific and clinical knowledge, optimize implant and prosthetic planning to achieve better and complication-free long-term outcomes.

\section{Conclusions}

Within the limitation of this literature review it can be concluded that fully edentulous patients restored with implant supported full-arch all-on-four prosthesis can be frequently affected by per-implant diseases. Fixed fullarch implant supported restorations are not problem-free solutions and certain maintenance aspects and protocols should be planned to improve soft and hard tissue longterm outcomes. Nevertheless, all-on-four concept prosthesis represents a most viable treatment option restoring function and esthetics and maintaining the patients' quality of life at satisfactory levels, with reduced cost and treatment time. Further prospective studies are needed with longer follow-up times, standardized evaluation criteria, and newer materials.

\section{Acknowledgments}

Funding: None.

\section{Footnote}

Provenance and Peer Review: This article was commissioned by the Guest Editor (Ole T. Jensen) for the series "Current Advances in Treatment of Peri-Implantitis" published in Frontiers of Oral and Maxillofacial Medicine. The article has undergone external peer review.

Reporting Checklist: The authors have completed the Narrative Review reporting checklist. Available at https://fomm. amegroups.com/article/view/10.21037/fomm-21-83/rc

Conflicts of Interest: Both authors have completed the ICMJE uniform disclosure form (available at https:// fomm.amegroups.com/article/view/10.21037/fomm-2183/coif). The series "Current Advances in Treatment of Peri-Implantitis" was commissioned by the editorial office without any funding or sponsorship. The authors have no other conflicts of interest to declare.

Ethical Statement: The authors are accountable for all aspects of the work in ensuring that questions related to the accuracy or integrity of any part of the work are appropriately investigated and resolved.

Open Access Statement: This is an Open Access article distributed in accordance with the Creative Commons Attribution-NonCommercial-NoDerivs 4.0 International License (CC BY-NC-ND 4.0), which permits the noncommercial replication and distribution of the article with the strict proviso that no changes or edits are made and the original work is properly cited (including links to both the formal publication through the relevant DOI and the license). See: https://creativecommons.org/licenses/by-nc-nd/4.0/.

\section{References}

1. Balshi TJ, Wolfinger GJ, Slauch RW, et al. A retrospective analysis of 800 Brånemark System implants following the All-on-Four ${ }^{\mathrm{TM}}$ protocol. J Prosthodont 2014;23:83-8.

2. Fischer K, Stenberg T. Prospective 10-year cohort study based on a randomized, controlled trial (RCT) on implant- 
supported full-arch maxillary prostheses. part II: prosthetic outcomes and maintenance. Clin Implant Dent Relat Res 2013;15:498-508.

3. Jemt T. Implant Survival in the Edentulous Jaw: 30 Years of Experience. Part II: A Retro-Prospective Multivariate Regression Analysis Related to Treated Arch and Implant Surface Roughness. Int J Prosthodont 2018;31:531-9.

4. Maló P, de Araújo Nobre M, Borges J, et al. Retrievable metal ceramic implant-supported fixed prostheses with milled titanium frameworks and all-ceramic crowns: retrospective clinical study with up to 10 years of followup. J Prosthodont 2012;21:256-64.

5. Papaspyridakos P, Mokti M, Chen CJ, et al. Implant and prosthodontic survival rates with implant fixed complete dental prostheses in the edentulous mandible after at least 5 years: a systematic review. Clin Implant Dent Relat Res 2014;16:705-17.

6. Maló P, de Araújo Nobre M, Lopes A, et al. "All-on-4" immediate-function concept for completely edentulous maxillae: a clinical report on the medium ( 3 years) and long-term (5 years) outcomes. Clin Implant Dent Relat Res 2012;14 Suppl 1:e139-50.

7. Malo P, de Araújo Nobre M, Lopes A, et al. A longitudinal study of the survival of All-on-4 implants in the mandible with up to 10 years of follow-up. J Am Dent Assoc 2011;142:310-20.

8. Papaspyridakos , Chen CJ, Singh M, et al. Success criteria in implant dentistry: a systematic review. J Dent Res 2012;91:242-8.

9. Ramanauskaite A, Galarraga-Vinueza ME, Obreja K, et al. Prevalence of Peri-implant Diseases in Patients with Full-Arch Implant-Supported Restorations: A Systematic Review. Int J Prosthodont 2021;34:s27-45.

10. Berglundh T, Armitage G, Araujo MG, et al. Peri-implant diseases and conditions: Consensus report of workgroup 4 of the 2017 World Workshop on the Classification of Periodontal and Peri-Implant Diseases and Conditions. J Clin Periodontol 2018;45 Suppl 20:S286-91.

11. Lang NP, Berglundh T; Working Group 4 of Seventh European Workshop on Periodontology. Periimplant diseases: where are we now?--Consensus of the Seventh European Workshop on Periodontology. J Clin Periodontol 2011;38 Suppl 11:178-81.

12. Socransky SS, Haffajee AD. Periodontal microbial ecology. Periodontol 2000 2005;38:135-87.

13. Schwarz F, Derks J, Monje A, et al. Peri-implantitis. J Periodontol 2018;89 Suppl 1:S267-90.

14. Katafuchi M, Weinstein BF, Leroux BG, et al. Restoration contour is a risk indicator for peri-implantitis: A crosssectional radiographic analysis. J Clin Periodontol 2018;45:225-32.

15. Yi Y, Koo KT, Schwarz F, et al. Association of prosthetic features and peri-implantitis: A cross-sectional study. J Clin Periodontol 2020;47:392-403.

16. English CE. Critical A-P spread. Implant Soc 1990;1:2-3.

17. Maló P, Rangert B, Nobre M. "All-on-Four" immediatefunction concept with Brånemark System implants for completely edentulous mandibles: a retrospective clinical study. Clin Implant Dent Relat Res. 2003;5 Suppl 1:2-9.

18. Maló P, de Araújo Nobre M, Lopes A, et al. All-on-4® Treatment Concept for the Rehabilitation of the Completely Edentulous Mandible: A 7-Year Clinical and 5-Year Radiographic Retrospective Case Series with Risk Assessment for Implant Failure and Marginal Bone Level. Clin Implant Dent Relat Res 2015;17 Suppl 2:e531-41.

19. Maló P, de Araújo Nobre M, Moura Guedes C, et al. Short-term report of an ongoing prospective cohort study evaluating the outcome of full-arch implant-supported fixed hybrid polyetheretherketone-acrylic resin prostheses and the All-on-Four concept. Clin Implant Dent Relat Res 2018;20:692-702.

20. Lindhe J, Meyle J; Group D of European Workshop on Periodontology. Peri-implant diseases: Consensus Report of the Sixth European Workshop on Periodontology. J Clin Periodontol 2008;35:282-5.

21. Caton JG, Armitage G, Berglundh T, et al. A new classification scheme for periodontal and peri-implant diseases and conditions - Introduction and key changes from the 1999 classification. J Periodontol 2018;89 Suppl 1:S1-8.

22. Heitz-Mayfield LJA, Salvi GE. Peri-implant mucositis. J Periodontol 2018;89 Suppl 1:S257-66.

23. Francetti L, Corbella S, Taschieri S, et al. Medium- and Long-Term Complications in Full-Arch Rehabilitations Supported by Upright and Tilted Implants. Clin Implant Dent Relat Res 2015;17:758-64.

24. Li S, Di P, Zhang Y, et al. Immediate implant and rehabilitation based on All-on-4 concept in patients with generalized aggressive periodontitis: A mediumterm prospective study. Clin Implant Dent Relat Res 2017;19:559-71.

25. Lopes A, Maló P, de Araújo Nobre M, et al. The NobelGuide ${ }^{\circledR}$ All-on-4® Treatment Concept for Rehabilitation of Edentulous Jaws: A Prospective Report on Medium- and Long-Term Outcomes. Clin Implant Dent Relat Res 2015;17 Suppl 2:e406-16.

26. Lopes A, Maló P, de Araújo Nobre M, et al. The 
NobelGuide® All-on-4® Treatment Concept for Rehabilitation of Edentulous Jaws: A Retrospective Report on the 7-Years Clinical and 5-Years Radiographic Outcomes. Clin Implant Dent Relat Res 2017;19:233-44.

27. Felton DA. Edentulism and comorbid factors. J Prosthodont 2009;18:88-96.

28. Krekmanov L, Kahn M, Rangert B, et al. Tilting of posterior mandibular and maxillary implants for improved prosthesis support. Int J Oral Maxillofac Implants 2000; 15:405-14.

29. Zarb GA, Albrektsson T. Consensus report: towards optimized treatment outcomes for dental implants. J Prosthet Dent 1998;80:641.

30. Zarb GA, Albrektsson T. Towards optimized treatment outcomes for dental implants. J Prosthet Dent 1998;80:639-40.

doi: 10.21037/fomm-21-83

Cite this article as: Margvelashvili-Malament M, Eckert SE. Prevalence of peri-implant diseases in fully edentulous patients restored with four implants supported fixed full arch prosthesis: a literature review. Front Oral Maxillofac Med 2022;4:7.
31. Corbella S, Del Fabbro M, Taschieri S, et al. Clinical evaluation of an implant maintenance protocol for the prevention of peri-implant diseases in patients treated with immediately loaded full-arch rehabilitations. Int J Dent Hyg 2011;9:216-22.

32. Felton DA. Complete Edentulism and Comorbid Diseases: An Update. J Prosthodont 2016;25:5-20.

33. Mathew MG, Samuel SR, Soni AJ, et al. Evaluation of adhesion of Streptococcus mutans, plaque accumulation on zirconia and stainless steel crowns, and surrounding gingival inflammation in primary molars: randomized controlled trial. Clin Oral Investig 2020;24:3275-80.

34. Margvelashvili-Malament M, Barbisan De-Souza A, Att W. Current workflows for computer-aided implant surgery: A review article. Curr Oral Health Rep 2019;6:295-305. 